

\section{DISCLAIMER}

This report was prepared as an account of work sponsored by an agency of the United States Government. Neither the United States Government nor any agency Thereof, nor any of their employees, makes any warranty, express or implied, or assumes any legal liability or responsibility for the accuracy, completeness, or usefulness of any information, apparatus, product, or process disclosed, or represents that its use would not infringe privately owned rights. Reference herein to any specific commercial product, process, or service by trade name, trademark, manufacturer, or otherwise does not necessarily constitute or imply its endorsement, recommendation, or favoring by the United States Government or any agency thereof. The views and opinions of authors expressed herein do not necessarily state or reflect those of the United States Government or any agency thereof. 


\section{DISCLAIMER}

Portions of this document may be illegible in electronic image products. Images are produced from the best available original document. 


\title{
A Summary of Neutron Measurements for the Viking Program
}

\author{
M. E. Anderson
}

Issued: August 15, 1975

\section{NOTICE}

This report was prepared as an account of work sponsored by the United States Government. Neither the United States nor the United States Energy Research and Development Administration, nor any of their employees, nor any of their contrectors, subcontrectors, or their employees, makes any warrenty, express or implied, or assumes any legal liability or responsibility for the accuracy, com-

pleteness or usefulness of any information, apparatus, product or process disclosed or represents that its use would not infringe privately owned rights.

PRINTED IN THE UNITED STATES OF AMERICA

Available from

National Technical information Service

U. S. Department of Commerce 5285 Port Roval Road

Springfield, Virginia 2216

Price: Printed Copy $\$ 4.00$; Microfiche $\$ 2.25$

\section{MONSANTO RESEARCH CORPORATION}

A Subsidiary of Monsanto Company

\section{mOUnD IABORATORY}

Miamisburg, Ohio

45342

operated for

\section{UNITED STATES ENERGY RESEARCH AND DEVELOPMENT ADMINISTRATION}

U.S. Government Contract No. AT-33-1-GEN-53 
DISTRIBUTION

EXTERNAI

TIC, UC-23

R. I. BOok, ERDA/ALO

D. K. Nowlin, ERDA/ALO

J. R. Roeder, ERDA/ALO

G. P. Dix, ERDA/DSNS

G. L. Kimba11, ERDA/DSNS

J. J. Lombardo, ERDA/DSNS

V. G. Redmond, ERDA/DSNS

B. J. Rock, ERDA/DSNS

R. I. Wainwright, ERDA/DAO

R. DuVal, ERDA/SFO

A. Schock, Fairchild Industries

R. G. Ivanoff, Jet Propulsion Laboratory

I. J. Mullins, LASL

J. H. Masson, Martin-Marietta

W. Glenny, NASA/ Langley

R. A. Russe11, NASA/Langley

W. P. Thomas, SLA

F.A. Schumann, Teledyne Isotopes

W. W. Wacht1, Teledyne Isotopes

\section{CONSULTANTS :}

C. F. Curtiss, University of Wisconsin

M. L. Curtis, Centerville, Ohio

H. W. Mattson, Monsanto Company

D. F. Griffing; Miami University

R. E. Miers Ft. Wayne, Indiana

G. W. Powe 11 Ohio State University

A. Shapiro, University of Cincinnati

H. F. Swift University of Dayton Research Institute

D. White, University of Pennsylvania

\section{INTERNAL}
M. E. Anderson
W. A. Bigler
R. K. Blauvelt
A. R. Campbell
W. T. Cave
T. C. Elswick
T. M. Flanagan
D. E. Friedline
F. X. Haas
E. W. Johnson
I. V. Jones

D. P. Kelly

J. F. Lemming

C. C. Mann

R. A. Neff

B. D. Scearce

W. H. Smith

R. E. Vallee

J. G. Villars

Publications

Library (20) 
TABLE OF CONTENTS

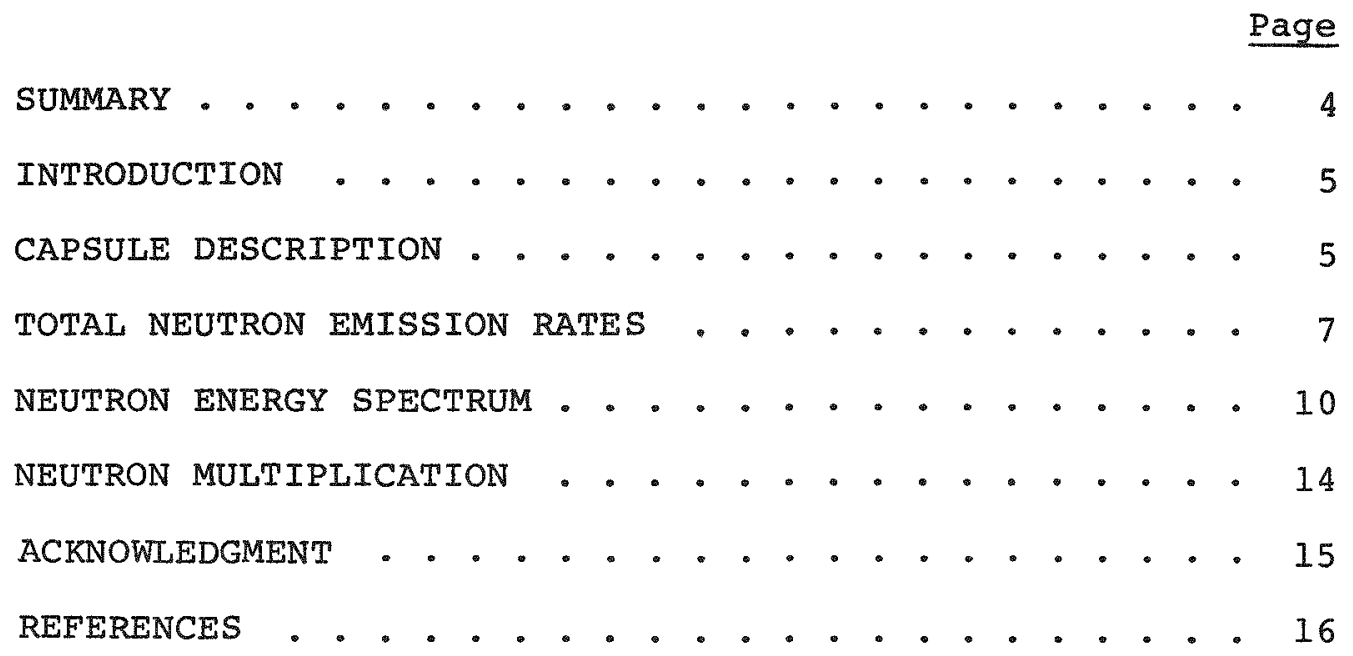




\section{SUMMARY}

The results of neutron measurements for plutonium-238-fueled, 683-W (thermal) capsules fabricated for the Viking Program (Mars Lander) are presented. These results include, for each capsule, the total neutron emission rate and neutron multiplication and, for one capsule, the neutron energy spectrum. A precision long counter was used for the neutron emission rate measurements and a single stilbene crystal for the neutron spectrum measurement. 


\section{INTRODUCTION}

In mid-1975 two spacecraft will be launched from Earth for a journey to Mars. These craft are part of the Viking Program designed to soft-land two scientific laboratories on the Red planet. Electrical energy for each laboratory will be provided by two radioisotopic-powered thermoelectric generators each containing a capsule fueled with $1.2 \mathrm{~kg}$ of plutonium-238 providing a thermal output of 683 W. Eight such capsules were assembled for this program and neutron measurements were performed on these capsules. These measurements include total emission rates for each capsule and a neutron energy spectrum for one capsule. Additionally, measurements and calculations relative to neutron multiplication within these capsules were also performed. Although eight capsules were assembled, only seven separate fuel stacks were prepared. Capsule VF-3 was opened subsequent to the neutron measurements and the fuel in it was used in $\mathrm{VF}-8$.

\section{CAPSULE DESCRIPTION}

The fuel in each viking capsule is a plutonium-molybdenum cermet having the composition 83 wt $8 \mathrm{PuO}_{2-\mathrm{x}}$ (with $\mathrm{x}$ varying from 0.05 to 0.1 ) and 17 wt $\%$ molybdenum. The plutonium is nominally $80 \%$ plutonium-238 and an approximate isotopic distribution for a typical fuel batch is shown in Table 1. Of the naturally occurring oxygen isotopes, only oxygen-17 and oxygen-18 will undergo $(\alpha, n)$ reactions*. In order to reduce the neutron yield, the oxygen in the fuel has been depleted in oxygen-17 and oxygen-18 by enriching it with oxygen-16.

\section{Table 1}

\section{APPROXIMATE ISOTOPIC COMPOSITION OF PLUTONIUM USED IN THE VIKING CAPSULES}

\begin{tabular}{lc} 
Isotope & Concentration (wt \%) \\
\hline${ }^{36} \mathrm{Pu}$ & $5 \times 10^{-5}$ \\
$2{ }^{38} \mathrm{Pu}$ & 80 \\
$2{ }^{39} \mathrm{Pu}$ & 16 \\
$2{ }^{40} \mathrm{Pu}$ & 3 \\
$2{ }^{41} \mathrm{Pu}$ & 1
\end{tabular}

\footnotetext{
*Whenever $(\alpha, n)$ is written in this report, it is meant to include the $(\alpha, n \gamma)$ reaction.
} 
The fuel, itself, was hot-pressed into pucks which are in the shape of either cylinders or truncated cones. Each capsule contains 18 pucks $0.54 \mathrm{~cm}$ thick and varying in maximum diameter from 3.83 to $5.37 \mathrm{~cm}$. Figure 1 is a drawing of the fuel stack with some dimensions shown. The left end puck has a cylindrical hole cut in it. Eighteen pucks do not fill up the inner volume of the capsule, and molybdenum shims were added between some of the pucks to take up the slack. The thickness of these shims and their locations are also shown in Figure 1 for the fuel stack for $V F-3$, the capsule for which the neutron spectrum was measured. A drawing of the capsule is shown in Figure 2. The PRD shown in Figure 2 is a device to relieve the helium buildup pressure resulting from alpha decay of the fuel.

During all neutron measurements each capsule was contained in a stainless steel container shown in Figure 3. The principal effect of this outer container on the neutron measurements is to alter the degree of anisotropy of the flux distribution about the capsule. Secondary effects are: slightly changed neutron emission rate and neutron energy spectrum. The neutron emission rate measurement procedure takes into account the anisotropy of emission, whatever its degree, so the effect is of little consequence other than it makes the difference in capsule geometry between the comparison standard and a VF capsule somewhat greater; this has been reflected in slightly increased uncertainty for the total neutron emission rate. The outer container will act as a reflector to those neutrons leaving the capsule and some of the reflected neutrons will result in additional fissioning of plutonium. Since few neutrons will be absorbed in the outer container, there should be a slight net increase in the total neutron emission rate. The neutron spectrum will

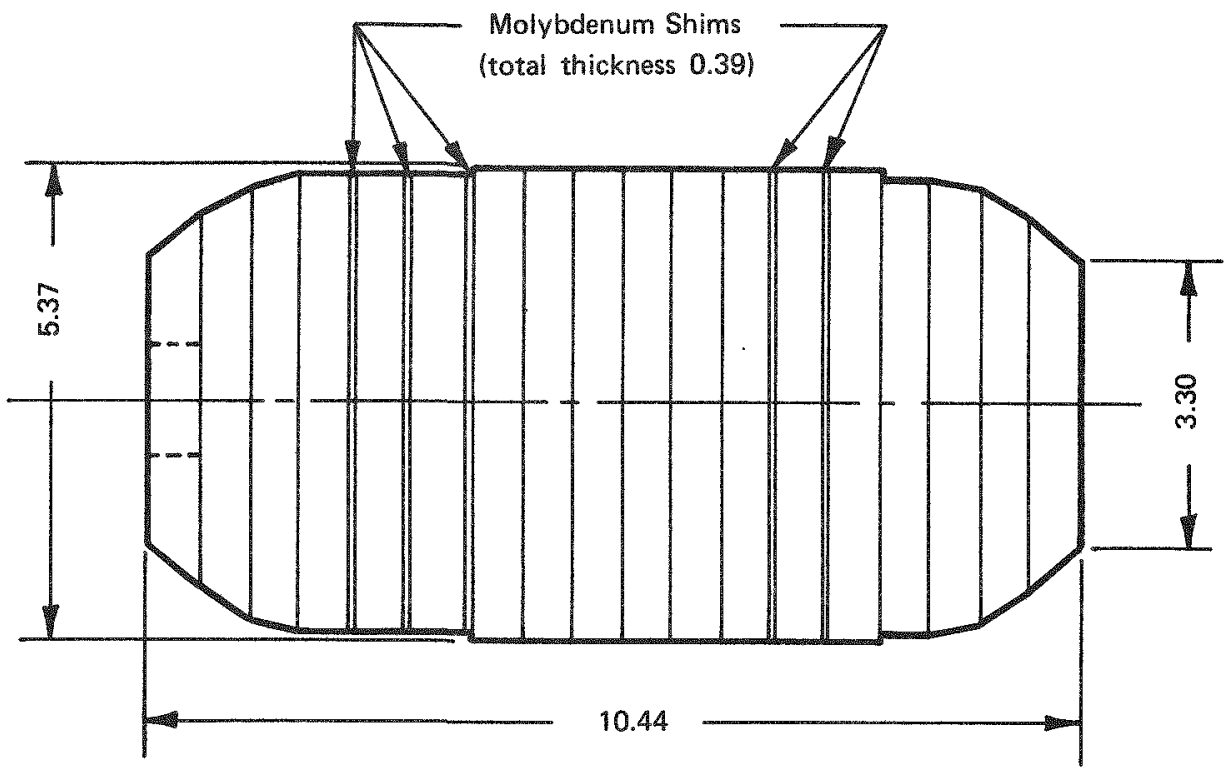

FIGURE I - Schematic of fuel stack for capsule VF-3 (alI dimensions are in centimeters). The only differences between this stack and those for other capsules are in the numbers and locations of the shims. 


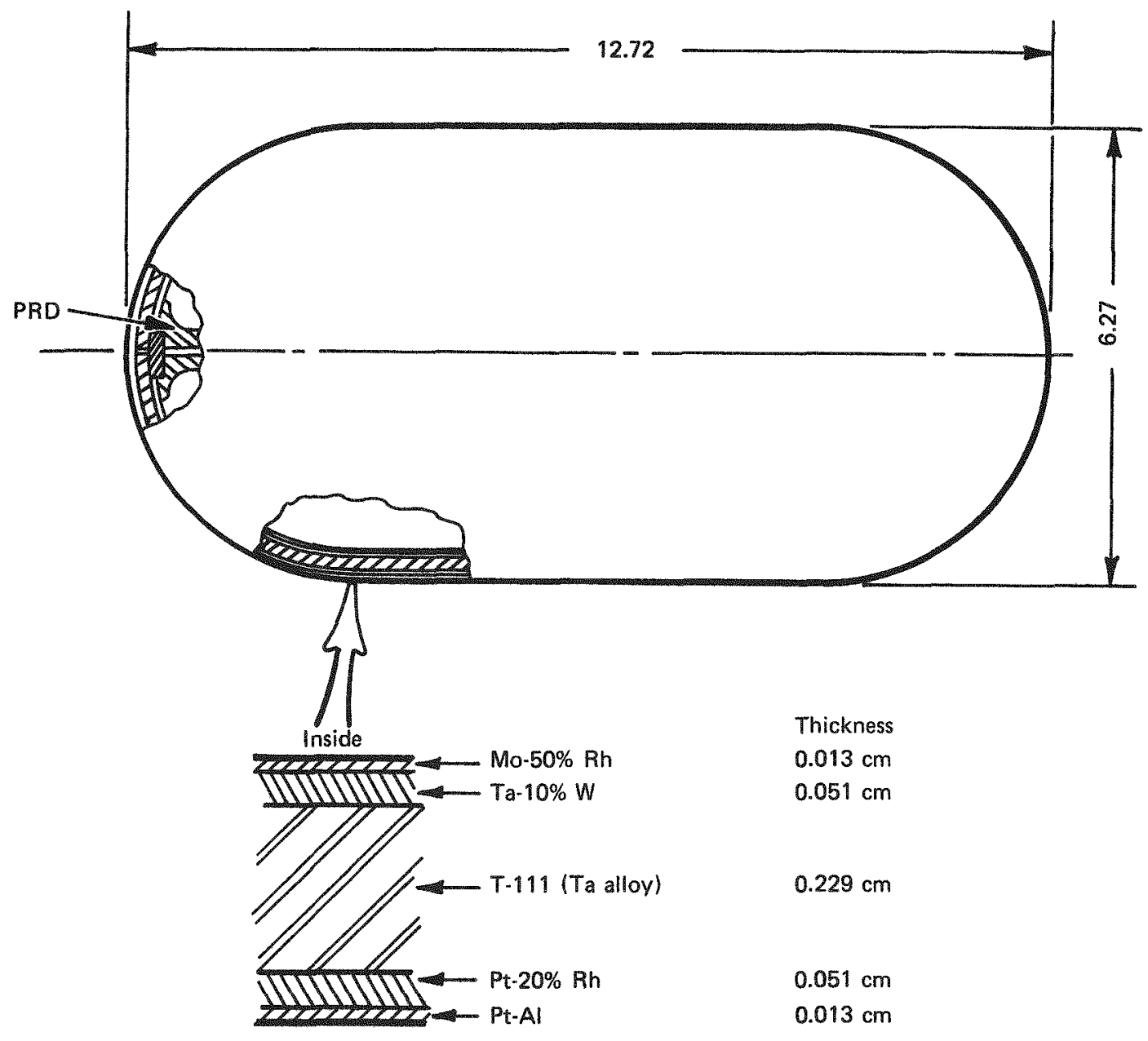

Construction Details

FIGURE 2 - Schematic of Viking capsule containers (all dimensions are in centimeters).

be slightly altered also, because of the added fission neutrons and some energy degradation of those neutrons scattered, principally inelastically, in the outer container.

\section{TOTAL NEUTRON EMISSION RATES}

Total neutron emission rates were determined by comparison with Pu-Be $(\alpha, n)$ capsule M-591 which had previously been calibrated at the National Bureau of Standards. The detector used for the comparison is a precision long counter (PLC). Comparison is made by successively placing each capsule on the axis of the PLC and approximately $100 \mathrm{~cm}$ from its effective center. The axes of the capsules and the PLC are coplanar and horizontal. Figure 4 is a photo of the PIC and the Viking capsule in its outer container on a rotator. The PLC and rotator are in the middle of a room which is $9 \mathrm{~m}$ long, $6 \mathrm{~m}$ wide and $5 \mathrm{~m}$ high. The floor in the middle of the room is $0.6-\mathrm{cm}-$ thick steel plate covering a $1.5-\mathrm{m}$-deep pit. The walls are made of hollow concrete block, the ceiling is light-weight metal, and the bottom of the pit is concrete. 


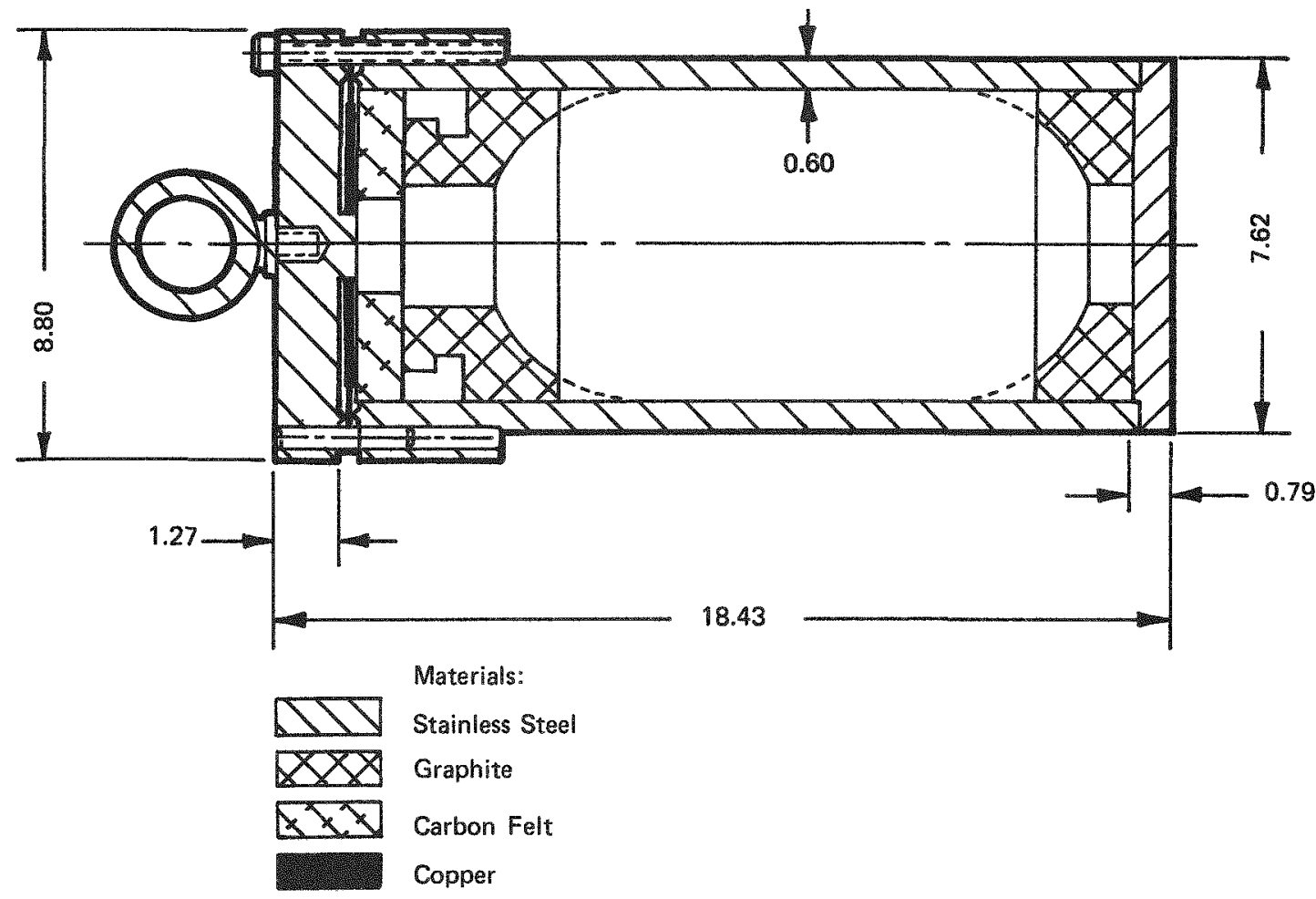

FIGURE 3 - Cross section of outer container used for housing Viking capsules during neutron measurements (all dimensions are in centimeters).

A measurement consists of rotating the capsule in steps about a vertical axis through its center and obtaining counting data at each step. The total neutron emission rate $Q$ for each capsule is related to the counting data by

$$
Q=R(E) \int_{0}^{\pi} \frac{[A(\theta)-S(\theta)] 2 \pi \sin \theta d \theta}{4 \pi}
$$

where $A(\theta)$ is the total counting rate corrected for resolving time losses at angle $\theta$, the angle between the source and PLC axes with $0^{\circ}$ being when both are colinear; $S(\theta)$ is the room-scattered neutron background including scattering from the capsule support; and $R(E)$ is the response of the PLC to the energy spectrum of the capsule being measured. $R(E)$ is determined from the measured neutron spectrum and a PIC response curve for monoenergetic neutrons. The integral is evaluated by Gauss's quadrature formula for seven points in the $0-\pi$ interval. A second measurement is made for the $\pi-2 \pi$ interval and the two are averaged.

Table 2 is a summary of total emission rates for the Viking capsules VF-1 through VF-8. The absolute uncertainty of each value is thought to be $\pm 5 \%$. This uncertainty is made up of the following:

Uncertainty in the value of the Pu-Be reference standard.

Counting statistics for the reference standard

$0.16 \%$ 


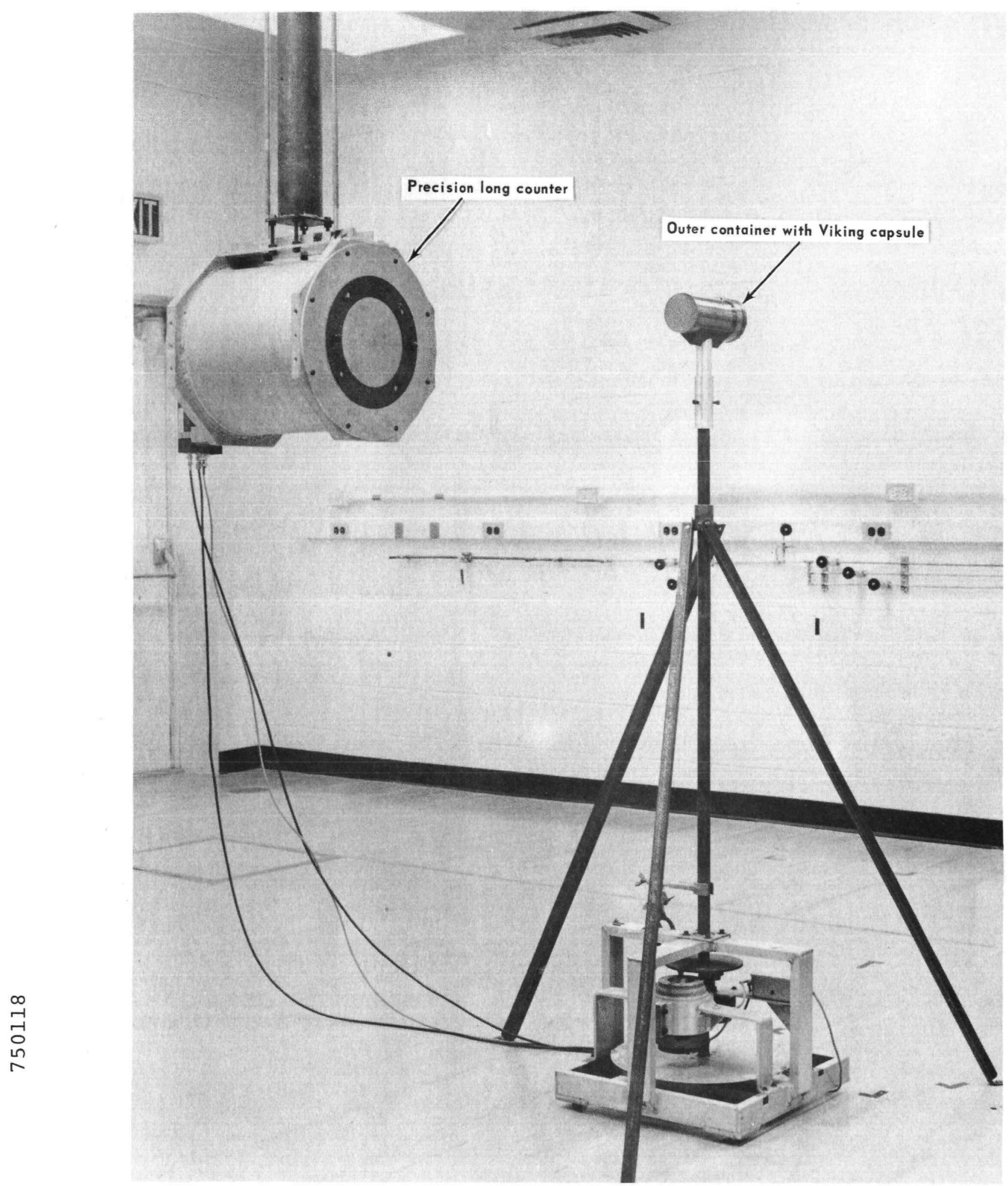

FIGURE 4 - A view of the precision long counter and the viking capsule in its outer container. 
Uncertainty arising from differences in the response factors and geometric factors between the viking capsule and the reference standard

The first three uncertainties were combined as the square root of the sum of the squares and the fourth was added directly to this. The relative uncertainty for the ratio of emission rates for any two capsules is less than $1 \%$. A check on the relative uncertainty is possible by taking the ratio between the values for $V F-3$ and $V F-8$ which contained the same fuel. When corrected for the differences in measurement dates, this ratio is

$$
\frac{Q(V F-8)}{Q(V F-3)}=1.0065
$$

Table 2

A SUMMARY OF TOTAL NEUTRON EMISSION RATES AND NEUTRON MULTIPLICATION WITHIN VIKING CAPSULES

\begin{tabular}{|c|c|c|c|}
\hline Capsule & $\begin{array}{l}\text { Total Neutron } \\
\text { Emission Rate } \\
(\mathrm{n} / \mathrm{sec}) \\
\end{array}$ & Date & $\begin{array}{l}\text { Multiplication } \\
\text { (from Equation 6) }\end{array}$ \\
\hline$V F-1$ & $8.16 \times 10^{6}$ & $9-18-73$ & 1.306 \\
\hline $\mathrm{VF}-2$ & $7.45 \times 10^{6}$ & $9-18-73$ & 1.293 \\
\hline$V F-3$ & $7.16 \times 10^{6}$ & $11-06-74$ & $1.280^{\mathrm{a}}$ \\
\hline$V F-4$ & $7.24 \times 10^{6}$ & $10-24-74$ & 1.273 \\
\hline$V F-5$ & $7.40 \times 10^{6}$ & $11-06-74$ & 1.287 \\
\hline$V F-6$ & $7.34 \times 10^{6}$ & $11-20-74$ & 1.285 \\
\hline$V F-7$ & $6.92 \times 10^{6}$ & $11-20-74$ & 1.281 \\
\hline$V F-8$ & $7.10 \times 10^{6}$ & $2-14-75$ & \\
\hline
\end{tabular}

\section{NEUTRON ENERGY SPECTRUM}

A single stilbene-crystal, fast-neutron spectrometer and a long counter were used for the spectral determinations. The stilbene spectrometer was used to obtain the greater-than-0.8-MeV portion of the spectrum. The portion of the spectrum with energies less than $0.8 \mathrm{MeV}$ was obtained by a difference calculation using the following two values: 1) the total neutron flux at the stilbene crystal calculated from measurements made with the long counter, and 2) the neutron flux for energies greater than $0.8 \mathrm{MeV}$ obtained from the stilbene data. The difference between these two values is then the neutron flux with energies less than 0.8 $\mathrm{MeV}$. All measurements were corrected for room-scattered neutron background by interspersing either a polyethylene or paraffin-filled shadow shield between the source and the detector. Figure 5 shows the experimental setup for the stilbene scattering measurement. The stilbene crystal used for all spectral measurements is $2 \mathrm{~cm}$ in diameter by $1 \mathrm{~cm}$ high and the detector-capsule separation was $100 \mathrm{~cm}$. 
750116

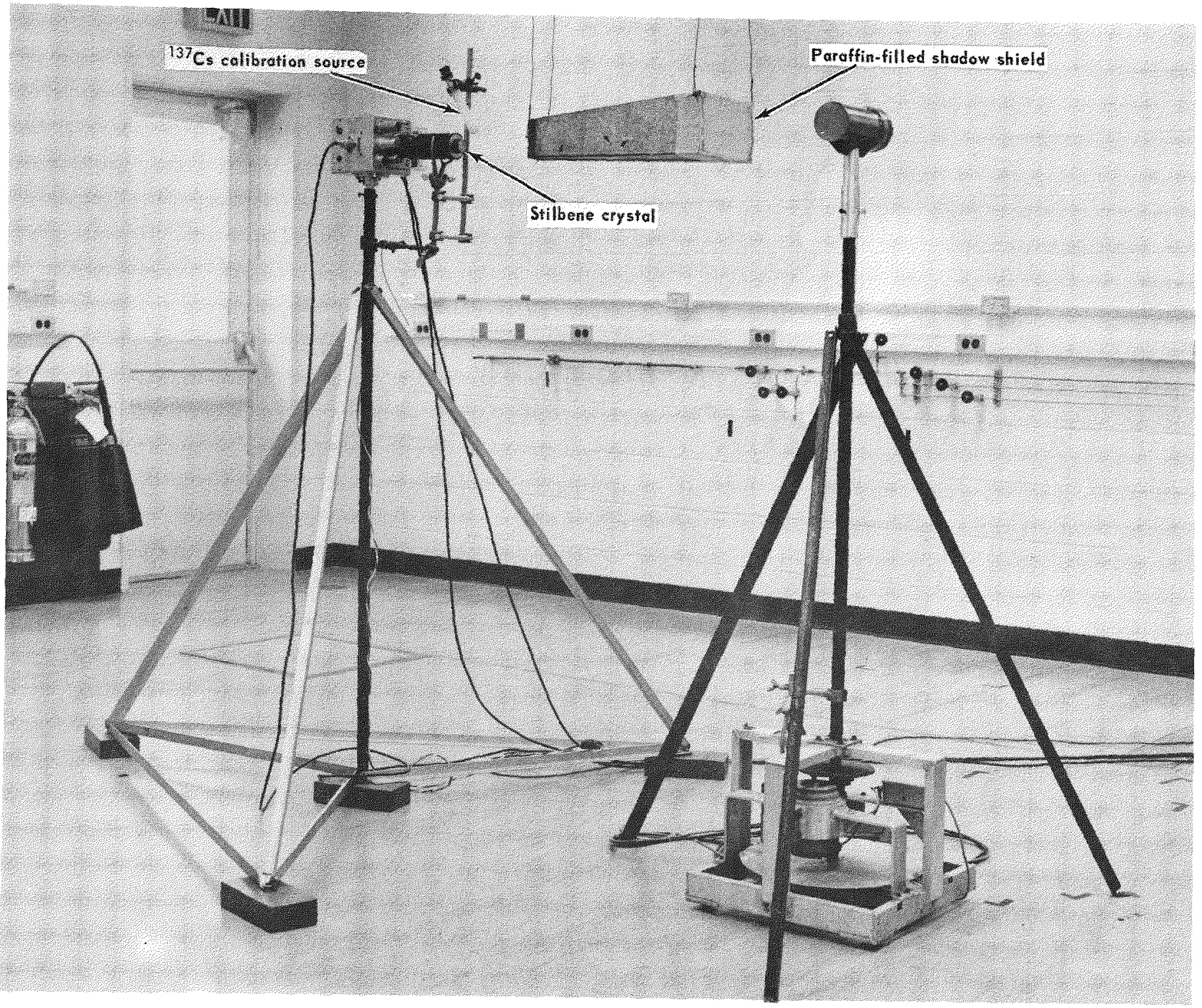

FIGURE 5 - A view of the experimental setup for the neutron spectrum scattering measurement. 
Pulse shape discrimination, utilizing space charge limitation at the last dynode of a 14-stage photomultiplier, was used to separate the pulses originating from neutron interactions in the crystal from those pulses originating from gamma interactions. Both amplitude and time requirements were used to define the gating pulses for the multichannel pulse height analyzer. Energy calibration of the spectrometer and the reduction procedure have been described elsewhere. ${ }^{2}$ Briefly, the energy calibration is based on the spectrum of $\mathrm{Pu}-\mathrm{Be}(\alpha, n)$ source $M-591$ as measured several years ago with nuclear emulsions. Routine energy calibration was made by using 662-kev gamma rays from the cesium-137 source shown in Figure 5 and $2615-\mathrm{keV}$ gamma rays from the capsule.

The measured spectrum is shown in Figure 6 . The data points for neutron energies greater than $0.8 \mathrm{MeV}$ were obtained with the stilbene spectrometer. The error bars for these data represent plus or minus one standard deviation and are from counting statistics only. Where no error bars are shown, the bars would be smaller than the data points. The datum point at 0.4 $\mathrm{MeV}$ was determined by the difference calculation. The error bar for this datum point is an estimate of the absolute uncertainty for the difference calculation.

The total specific neutron yield for $\mathrm{VF}-3$ is $6000 \pm 300 \mathrm{n} / \mathrm{sec}-\mathrm{g}\left({ }^{23}{ }^{8} \mathrm{Pu}\right)$ and is composed of neutrons from the following principal sources: spontaneous fission of plutonium, chiefly plutonium-238; neutron-induced fission of plutonium; and $(\alpha, n)$ reactions with oxygen and other lowatomic-number elements.

The average specific neutron yield for the fuel used in this capsule is $4650 \pm 230 \mathrm{n} / \mathrm{sec}-\mathrm{g}\left({ }^{2}{ }^{3} \mathrm{Pu}\right)$. An estimate of the number of neutrons from each of the primary neutron sources has been made by comparing this spectrum with previous (unpublished) work. These values are:

$$
\begin{array}{ll}
\text { Spontaneous fission of plutonium } & 2650 \pm 150 \mathrm{n} / \mathrm{sec}-\mathrm{g}\left({ }^{238} \mathrm{Pu}\right) \\
(\alpha, n) \text { reactions with oxygen } & 1250 \pm 200 \mathrm{n} / \mathrm{sec}-\mathrm{g}\left({ }^{238} \mathrm{Pu}\right) \\
(\alpha, n) \text { reactions with other low- } & \\
\quad \text { atomic-number elements } & 750 \pm 340 \mathrm{n} / \mathrm{sec}-\mathrm{g}\left({ }^{2{ }^{3} \mathrm{P}} \mathrm{Pu}\right)
\end{array}
$$

The uncertainty shown for spontaneous fission is an estimate based on the earlier work while that for oxygen is based on the calculations which entered into the oxygen source calculation. The yield for other $(\alpha, n)$ reactions $(750)$ is from $4650-(2650+1250)$ and the uncertainty $( \pm 340)$ is from $\left(230^{2}+150^{\frac{1}{2}}+200^{2}\right)^{\frac{1}{2}}$.

The average energy for this spectrum, defined as

$$
\bar{E}=\frac{\int_{0}^{\infty} E N(E) d E}{\int_{0}^{\infty} N(E) d E}
$$

where $N(E)$ is the measured neutron spectrum, is $1.66 \pm 0.05 \mathrm{MeV}$.

The average neutron dose equivalent factor, defined as

$$
\bar{a}_{e}=\frac{\int_{0}^{\infty} a_{e}(E) N(E) d E}{\int_{0}^{\infty} N(E) d E}
$$




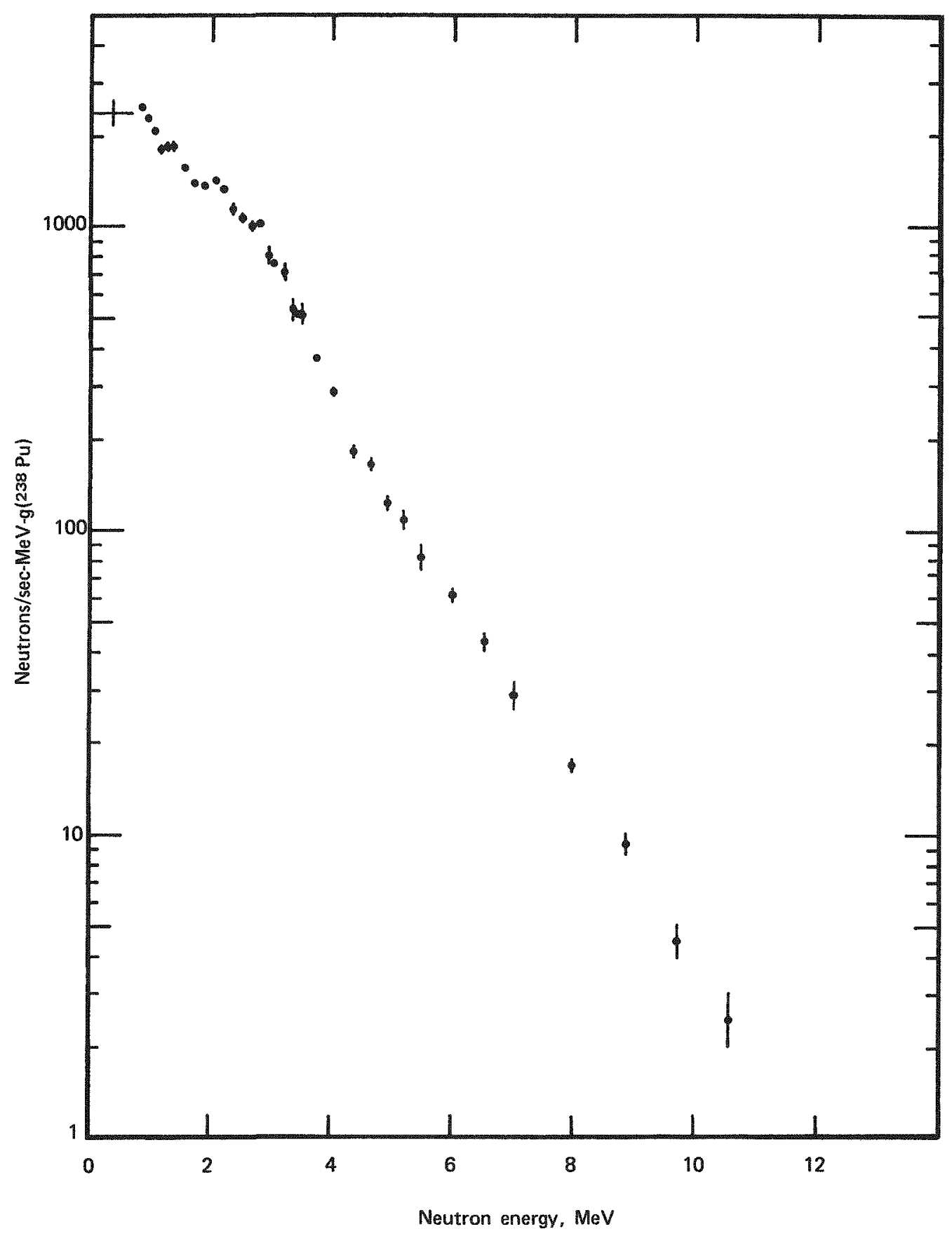

FIGURE 6 - Neutron energy spectrum of Viking capsule VF-3. 
where $d_{e}(E)$ are the neutron fluence-to-dose equivalent factors for monoenergetic neutrons, ${ }^{3}$ is $(3.08 \pm 0.24) \times 10^{-5} \mathrm{mrem} / \mathrm{n}-\mathrm{cm}^{-2}$. Dose equivalent rates at different distances $\underline{r}$ from a capsule, $\underline{r}$ being great enough that the capsule behaves as a point source of neutrons, may be given by

$$
\frac{\Delta D_{e}}{\Delta t}=\frac{Q \varepsilon(\theta) \bar{d}_{e}}{4 \pi r^{2}}
$$

where:

$$
\varepsilon(\theta)=\frac{g(\theta)}{Q / 4 \pi}
$$

with $q(\theta)$ being the neutron emission rate per steradian in direction $\theta$. For the VF series, with the capsules in the outer containers, $\varepsilon\left(90^{\circ}\right)=$ $1.16 \pm 0.01$.

\section{NEUTRON MULTTPLICATION}

Neutron multiplication $M$ within a capsule is defined as

$$
M=\frac{Q}{\sum_{i=1}^{n} Q_{i}}
$$

where $Q$ is the total neutron emission rate for the capsule as described earlier in this report, $Q_{i}$ is the total neutron emission rate for a puck corrected for multiplication within the puck, and $\underline{n}$ is the number of pucks. The multiplication within a puck ${ }^{4}$ was determined from

$$
M^{\prime}=1+\frac{\left(\Sigma_{P} / \Sigma_{T}\right) P_{c}}{1-\left(1+\Sigma_{P} / \Sigma_{T}\right) P_{c}}
$$

where $\Sigma_{T}$ is the macroscopic total neutron cross section and $\Sigma_{\mathrm{P}}$ is the so-called "production cross section." $\Sigma_{\mathrm{P}}$ is defined as

$$
\Sigma_{\mathrm{P}}=(\nu-1-\alpha) \Sigma_{\mathrm{F}}
$$

where $\nu$ is the average number of neutrons released per fission, $\alpha$ is the ratio of the nonfission-to-fission capture cross sections, and $\Sigma_{F}$ is the macroscopic fission cross section. In Equation 7, the uniform source collision probability is defined as

$$
P_{c}=\frac{1}{V} \int_{V}\left(1-e^{-\Sigma_{T} x}\right) d V
$$

where $x$ is the straight path distance from the volume element $d V$ to the fuel boundary.

Implicit in Equation 7 is the approximation that values for $\Sigma_{P}, \Sigma_{T}$, and $\mathrm{P}_{\mathrm{c}}$ do not change for successive neutron generations [the first generation being comprised of neutrons from $(\alpha, n)$ reactions and spontaneous fission of plutonium-238, the second and succeeding generations being neutrons from induced fission]. Checks have shown that this approximation does 
not significantly affect the results. The value for $\Sigma_{\mathrm{P}}\left(0.092 \mathrm{~cm}^{-1}\right)$ was obtained from the measured multiplication and Equation 7, assuming the fuel volume of the capsule is a right cylinder $5.18 \mathrm{~cm}$ in diameter and $10.44 \mathrm{~cm}$ high. The value for $\Sigma_{T}\left(0.352 \mathrm{~cm}^{-1}\right)$ is from measured cross sections and the spectrum shown in Figure 6. Calculated multiplications for the individual pucks in the VF capsules ranged from 1.034 to 1.042 with estimated uncertainties of \pm 0.01 .

The presence of all containments for the capsule and the individual pucks has been ignored in all multiplication calculations. The effect of this on the calculations should be small since: 1) both the capsules and pucks were contained in roughly the same type of container - therefore, the fractional increases in multiplication should be approximately the same for both - and 2) any increases in multiplication due to the containment are only a small part of the total multiplication.

Measured multiplications for the VF series of capsules are also listed in Table 2. The uncertainty for these values, based on counting statistics, is $\pm 0.4 \%$ and the total uncertainty is estimated to be $\pm 2 \%$. Some differences between these values may be real. For example, the emission rate for VF-1 is about $12 \%$ greater than the average for the rest of the capsules. These additional neutrons are likely from the $O(\alpha, n)$ reaction which has a higher average energy (2.I MeV) than the other primary neutron sources: spontaneous fission (2.0 MeV) and the most likely other $(\alpha, n)$ reaction, $F(\alpha, n)(1.2 \mathrm{MeV})$. The production cross section for $\mathrm{VF}-1$ is therefore quite likely to be greater than it is for other capsules and this would result in a higher value for the multiplication than for the rest.

\section{ACKNOWLEDGMENT}

The assistance of Margaret Bolton with the neutron emission measurements is gratefully appreciated. 


\section{REFERENCES}

1. J. De Pangher and I. I. Nichols, A Precision Long Counter for Measuring Fast Neutron Flux, BNWL-260, Pacific Northwest Laboratory (1966).

2. M. E. Anderson and R. A. Neff, Nuclear Applications, $7: 1,62-66$ (1969).

3. Protection Against Neutron Radiation, NCRP Report No. 38, National Council on Radiation Protection and Measurements (1971).

4. See, for instance, p. 486 of Introductory Nuclear Reactor Theory by H. S. Isbin, Reinhold publishing Corporation, New York (1963).

5. R. A. Neff, M. E. Anderson, A. R. Campbell and F. X. Haas, "Some Neutron and Gamma Radiation Characteristics of Plutonium Cermet Fuel for Isotopic Power Sources," in Proceedings of the National Symposium on Natural and Man-Made Radiation in Space, NASA TM X2440 (1972), pp. 853-858. 